\title{
EROSION OF OROGENIC WEDGES - A SANDBOX VIEW K.S.PERSSON ${ }^{1} \&$ D. SOKOUTIS ${ }^{2}$
}

\begin{abstract}
Sandbox models give insights into the progressive development of two-sided orogenic wedges. Effective indenters, that develop in models without erosion for rigid indenter face-dips of $75^{\circ}$ or $15^{\circ}$, are strongly affected by erosion. No effective indenters develop in models with moderate and total erosion when the rigid indenter face-dip is $75^{\circ}$. In models with rigid indenter face-dips of $15^{\circ}$ effective indenters develop but are smaller in size when erosion is applied. If the effective indenter is smaller, strain partitioning by compaction decreases in favor of strain partitioning by imbricate shear. Models with rigid indenter face-dips of $15^{\circ}$ and $30^{\circ}$ and without redeposition favor strain partitioning by development of new shears.
\end{abstract}

KEY WORDS: effective indenter, erosion, orogenic wedge, sandbox modelling

\section{INTRODUCTION}

During indentation different ratios of vertical to lateral escape depend on the degree of orogen-lateral confinement of the indented continent (Davy and Cobbolt, 1988), the layer rheologies, and the dimensions of indented and indenting continents. Strong orogen confinement leads to crustal thickening while weak lateral confinement favors lateral escape (Davy and Cobbold, 1988; Ratschbacher et al, 1991). The exhumation of highgrade metamorphic rocks from continental convergence zones is also related to tectonic denudation and/or erosion (Koons, 1990; Thompson et al., 1997) in company with isostatic adjustment (Merle, 1994). Denudation unroofs orogens and exhumes material from within the orogen in proportion to the mass removed.

Erosion (mechanical and chemical) has mainly been considered a passive process, not one that can control tectonic evolution. However, in nature several orogens that suffer severe erosion show a high exhumation rate (Koons, 1990). Furthermore, redistribution of the eroded material by sedimentation can increase the vertical principal stresses on the foreland and hinterland. The rate of erosion is dependent on such factors as climate, rock-type, topography and rate of convergence.

This project focuses on the importance of erosional control of orogenic patterns of shear. Sandbox models with strong orogen lateral confinements leading to crustal thickening, by vertical movement due to indentation are subject to erosion and sedimentation at three different rates. Serial sectioning of such 3D sand-box experiments can give insight on deep-level structures for which we otherwise rely on geophysical profiles.

\section{PREVIOUS MODELLING AND TERMINOLOGY}

In continental convergence zones where the indenting and indented plates are of approximately the same vertical dimensions, the rising wedge can spread equally over both continents creating a two-sided coupled orogenic wedge (Koons, 1990 \& Beaumont et al., 1992). This "pop-up" wedge, bound by fore- and back kinks is typical for materials with an internal friction angle of $30^{\circ}$ (Coletta et al., 1991). The orogenic wedge is represented in the model as the area between the active fore-kink and back-kink (Fig. 1).

Strain localizes in sand on small-scale fault-like structures (Willett et al., 1993), called kink-bands (or kinks). Kink-bands start to dilate and shear with finite width but progressively narrow to shears and further to thrust zones. The definition of fore-kink and back-kink in this work follows Malavieille (1984) and is based on the direction of movement of the rigid indenter. Structures which propagate forward away from the advancing rigid indenter with progressive shortening, are called fore-kinks; those that propagate backward toward the indenter are called back-kinks (Fig. 1).

1. Ramberg Tectonic Laboratory, Uppsala University, Sweden

2. Dept. of Geology and Physical Geography, Aristotle University of Thessaloniki, Greece 


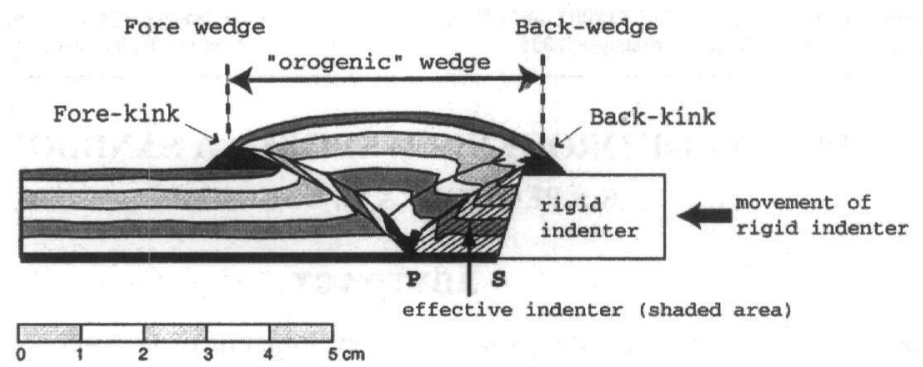

\section{Figure 1. Orogenic wedge bound by fore- and back-kinks where the back-kink is the front face of an effective indenter.}

The deformation mechanisms within the sand pack are lateral compaction, basal slip and imbricate shear or kinking (Mulugeta, 1988; Mulugeta and Koyi, 1987 \& 1992). The wedge rises stepwise and each of these incremental rises predates the formation of a new kink (Mulugeta and Koyi, 1992).

Most analogue models of indentation tectonics have considered the indenter geometry in plan view (e.g. Tapponier \& Molnar, 1976; Tapponier et al., 1982, 1986; Ratschbacher et al., 1991). However, recent models show that the structures in sand packs greatly depend on the vertical shape of the rigid indenter (Bonini et al., $1999 \&$ Persson, in press). For rigid ramp dips of $=60^{\circ}$ (Bonini et al., 1999) and $<30^{\circ}$ (Persson, in press), sand is transferred to the front of the rigid indenter, so that the system builds its own ramp, an effective indenter, by accreting and compacting sand between the rigid indenter and an active back-shear. The back-shear is taken to be the front face of the "effective indenter" (Fig. 1) (Bonini et al., 1999) and has a dip controlled by the angle of internal friction of the sand. The back-shear propagates simultaneously with a fore-kink from a line along the base of the sand pack. The line, representing the toe of the effective indenter, intersects vertical longitudinal profiles at a "P" -or Propagation point (Fig. 1) (Bonini et al., 1999). The P-point is also a separation point between slipped and unslipped zones of dicollement and is equivalent to the velocity discontinuity, or S-point (i.e. here the toe of the rigid indenter), in numerical models by Beaumont et al.'s, (1994). Combining results from Bonini et al., (1999) and Persson (in press), three groups develop (Fig. 2); those with an effective indenter in front of low angle rigid indenters with face dips of $15^{\circ}$ where " $\mathrm{P}$ " and "S" points coincide, those where the rigid indenters are sufficiently close to the internal friction of the sand that no effective indenter develop, and those that develop an effective indenter in front of the rigid indenter when the rigid indenter face-dip is $>45^{\circ}$ and "P" and "S" do not coincide.

The set of experiments described here used rigid indenters with front face-dips ( $\mathrm{f}$ in figure 2 ) of $15^{\circ}, 30^{\circ}$ and $75^{\circ}$ to study the influence of erosion on the development of effective indenters. Three different front face angles were chosen in order to represent the different groups distinguished above (Fig. 2).

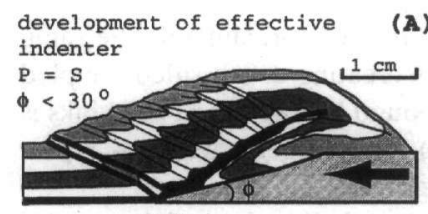

$P, S$
(A)

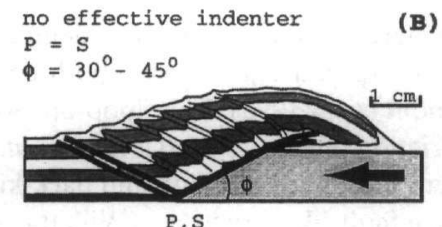

(B)

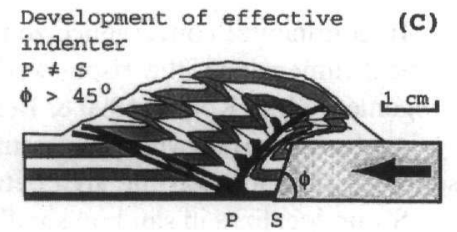

Figure 2. Models divided into three groups after Bonini et al., (1999) and Persson (in press).

\section{EXPERIMENTAL MATERIAL, DESIGN AND PROCEDURE}

Dry quartz sand, a Mohr-Coulomb material and a mean $30^{\circ}$ angle of internal friction, was used to represent the brittle behavior in the upper continental crust (Byerlee, 1978). Models with horizontal dimensions of $9.5 \times 7$ $\mathrm{cm}$ and vertical thickness $1.0 \mathrm{~cm}$ were built in a Plexiglas-box. The models were focused on the deformation of brittle upper crust decoupled from its underlying ductile crust above a detachment surface represented by the Plexiglas floor of the squeezebox. Sand of different colors was sedimented in the box to build the hanging wall. The color layers were passive and inserted in order to visualize the internal deformation pattern.

A rigid plastic block, representing cool crust of higher strength, was driven laterally into the sand-pack at a 
constant displacement rate of $1.8 \mathrm{~cm} \mathrm{~h}^{-1}$ up to $40 \%$ bulk lateral shortening. A value of 0.35 for the basal friction coefficient between the sand and Plexiglas was measured.

After every $4 \mathrm{~mm}$ increment of lateral shortening, the top portion of the extruding "orogenic" wedge was spread symmetrically both forward and backward to simulate erosion of the orogenic wedge with sedimentation prograding toward both sides. Three erosion-rates were applied; a) limited erosion, b) moderate erosion and c) total erosion. The vertical rise of the sand wedge during compression is dependent on the rigid indenter geometry (Persson, in press). Wedges in models with a rigid indenter front face-dip (f) of $75^{\circ}$ rise higher than models of $30^{\circ}$ and $15^{\circ}$ (Fig. 3). Different amounts of erosion were therefore applied in relation to the face-dip of the rigid indenter. Limited erosion was where the vertical rise of the sand wedge was allowed to grow in increments $1.5 \mathrm{~mm}$ when the indenter face-dip was $75^{\circ}, 1.25 \mathrm{~mm}$ for rigid indenters of $30^{\circ}$ and $1.0 \mathrm{~mm}$ for rigid indenters of $15^{\circ}$, before each phase of erosion. For moderate erosion the height increments were $1.0 \mathrm{~mm}$ for rigid indenter face-dips of $75^{\circ}, 0.5 \mathrm{~mm}$ for $15^{\circ}$ and $0.75 \mathrm{~mm}$ for $30^{\circ}$. Total erosion kept the sand wedge at the initial level of 1.0 $\mathrm{cm}$ throughout the whole deformation and the eroded material was removed.

After shortening, the models were cut to observe serial longitudinal cross-sections.

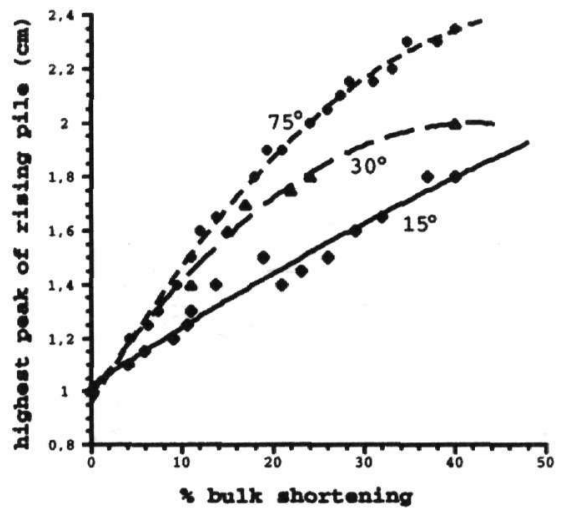

Figure 3. Height of rising pile with progressive bulk lateral shortening for models with rigid indenter dip of $15^{\circ}$, $30^{\circ}$ and $75^{\circ}$. (Persson in press)

\section{LIMITATIONS}

Increase in vertical loading, by extrusion of the orogenic wedge, would normally result in isostatic adjustment and depression of the thrust plane on a crustal scale. This factor was not taken into account. The models were designed to focus on the brittle deformation of the upper crust and took no account of any ductile strain within the extruded material. Temperature variations have not been considered either. The indenter was rigid and could not deform as the stronger plate might deform in nature.

In the models described here the erosion applied to both sides of the wedge was the same even though it is known that mountain ranges characteristically have asymmetric rainfall patterns.

\section{RESULTS}

During the first increments of displacement the sand compacts laterally and the sand pack close to the indenter thickens slightly above the dicollement. Steady advance of the rigid indenter induces a horizontal force that overcomes the basal friction leading to slip along the dicollement. Color layers in the sand start to develop a back-kink and a fore-kink that later narrow to shears. When the wedge reaches criticality, i.e. when the imbricate shears bind up because of the increased weight of the wedge, a new slip occurs along the basal dicollement. The area in front of the first fore-kink compacts laterally and the strain again localizes to a new fore-kink while the previous fore-kink inactivates, steepens and is pushed up the active back-shear. In all models, independent of rigid indenter face-dip, the back kinks narrows to a single back-shear along which successive developed forekinks are carried. 


\section{Models with rigid indenter face-dips of $75^{\circ}$}

In models with no applied erosion and rigid indenter face-dips of $75^{\circ}$, kinks nucleated at a P-point in front of the rigid toe (Fig. 4). By $20 \%$ bulk shortening, a back-shear started to form along which inactive fore-kinks were carried upward as new fore-kinks developed. By $40 \%$ bulk shortening 4 fore-kinks had developed. The last-developed back-shear clearly defined the frontal part of the effective indenter, now with a dip of about $50^{\circ}$ (Fig. 4).

In models with limited erosion the first fore-kink remained active until $17 \%$ bulk shortening when a second formed. The second fore-kink developed into a fore-shear that was still active by $40 \%$ bulk shortening whereas models without erosion had initiated a fourth fore-kink by $40 \%$ bulk shortening. The back-shear defining the effective indenter was much steeper than in the non-erosion case (Fig. 4). Another effect of limited erosion was that at $40 \%$ bulk shortening, the initial position of the P-point, which was significantly in front of the rigid ramp in models without erosion, now coincided with the S-point at the toe of the rigid ramp (Fig. 4).

In the model with moderate erosion 3 fore-kinks developed, at $4 \%, 21 \%$ and $38 \%$ bulk shortening, respectively. By $40 \%$ bulk shortening, the front face of the rigid indenter acted as a single back-shear and no effective indenter was visible. Steepening of the lower parts of the fore-kinks was less pronounced than in the model without erosion and limited erosion (Fig. 4).

In models with total erosion the first fore-kink remained active until $17 \%$ bulk shortening when the second developed. By $40 \%$ bulk shortening the second was still active and now developed into a fore-shear. No effective indenter developed and the front face of the rigid indenter acted as the only active back-shear throughout the deformation (Fig. 4).

Before deformation

With no applied erosion
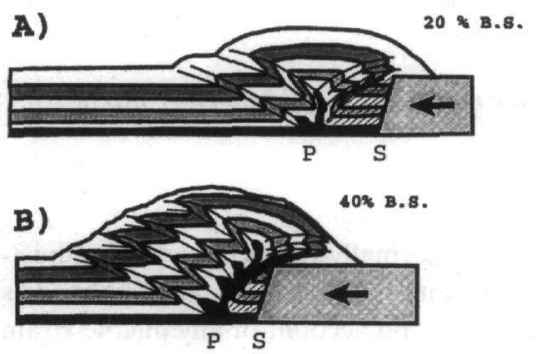

After moderate erosion

A)

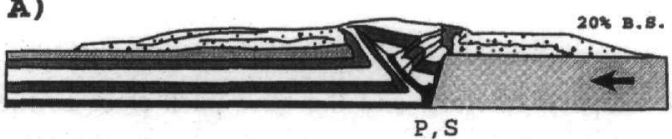

$$
P, S
$$

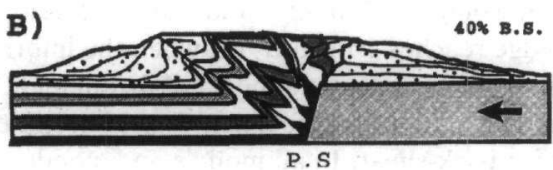

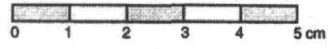

After limited erosion
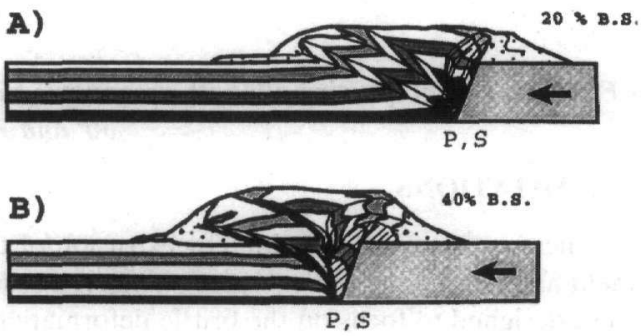

After total erosion

A)

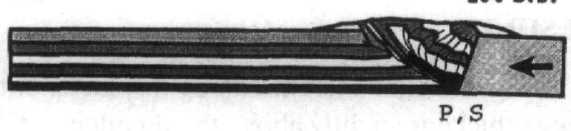

B) $40 \%$ B.8.

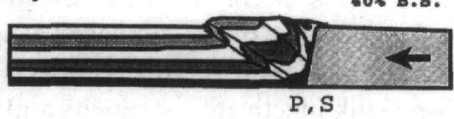

Figure 4. Summary sketches of models with rigid indenter face dips of $75^{\circ}$. 


\section{Models with rigid indenter face-dips of $30^{\circ}$}

All models developed 4 fore-kinks by $20 \%$ bulk shortening except models with total erosion that developed 5 fore-kinks (Fig. 5). By $40 \%$ bulk shortening all models developed 7 fore-kinks (Fig. 5). However, the number of fore-kinks developed by models with total erosion was obscured as the top fore-kinks were already eliminated by erosion. Only 5 fore-kinks were still visible. All models used the rigid indenter face as the active plane of back-shear.

\section{Before deformation}

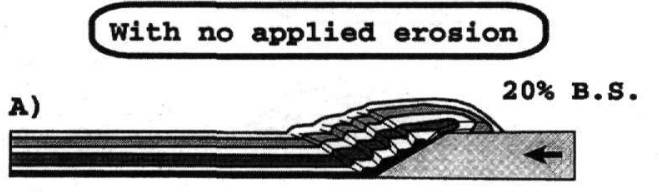

B)

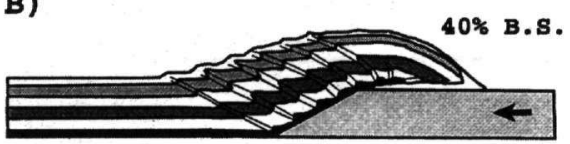

After moderate erosion

A)

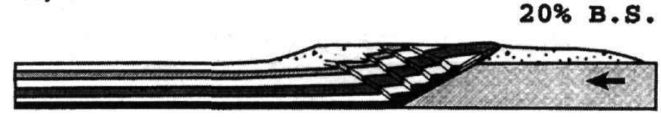

B)

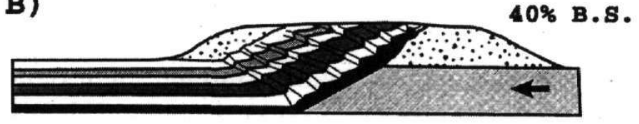

\section{After limited erosion}
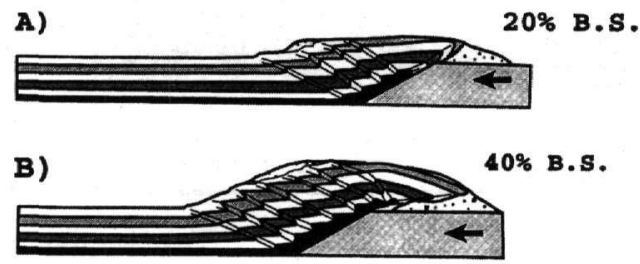

After total erosion

A)

$20 \%$ B.S.
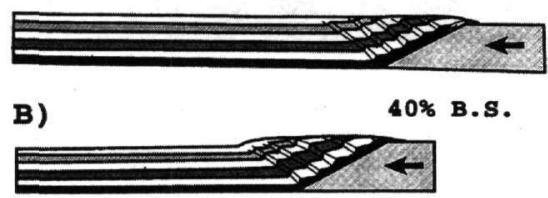

Figure 4. Summary sketches of models with rigid indenter face dips of $30^{\circ}$.

\section{Models with rigid indenter face-dips of $15^{\circ}$}

All models developed 3 fore-kinks and one back-shear by $20 \%$ bulk shortening (Fig. 6). By $40 \%$ bulk shortening only the model with total erosion differed from the others and developed 7 instead of 6 fore-kinks (Fig. 6). All models where erosion was applied developed smaller effective indenters than models without erosion (Fig. 6).

\section{DISCUSSION AND CONCLUSIONS}

Erosion and re-deposition is of significant importance in the development of thrust patterns and extrusion rate of orogenic wedges. Erosion and re-deposition change the pattern into which the orogenic wedge partition strain. Models with rigid indenter face-dips of $75^{\circ}$ produce fewer fore-kinks/shears that remain active for longer if erosion is applied. As the load on the shear plane is decreased, friction is no longer adequate to lock movement along it (cf. also Merle and Abidi, 1995). Local redeposition of the eroded material increases the vertical load further from the wedge and contributes to the higher efficiency of strain partitioning along the existing shear plane instead of developing a new kink at the margin affected by the additional loading. However, not all models produce fewer fore-kinks during erosion. Models with rigid indenter face-dips of $15^{\circ}$ and with total erosion develop one additional fore-kink by $40 \%$ bulk shortening compared to models without erosion, limited erosion and moderate erosion. These models develop a very small effective indenter, and the volume of sand to laterally compact is therefore also smaller favoring strain partitioning by imbricate shear rather than compaction. The growth of effective indenters is therefore dependent on the amount of erosion applied. Only in convergence zones with limited or no erosion are well developed effective indenters clear. For models with rigid indenter dips 


\section{With no applied erosion}
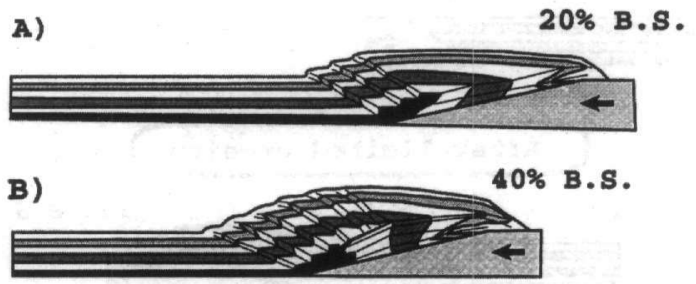

\section{After moderate erosion}

A)
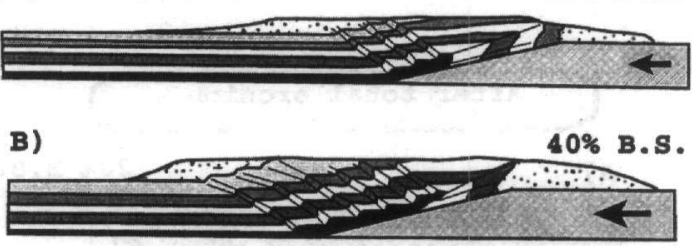

After limited erosion

A)

$20 \%$ B.S.

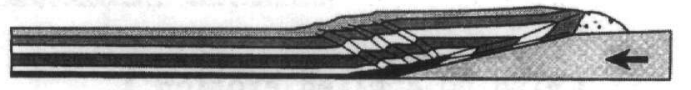

B)

$40 \%$ B.S.

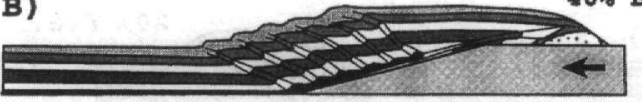

After total erosion

A)

$20 \%$ B.S.

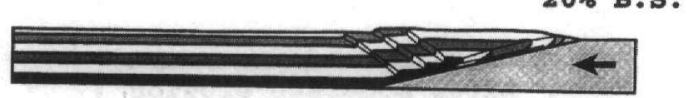

B)

$40 \%$ B.S.

Figure 4. Summary sketches of models with rigid indenter face dips of $15^{\circ}$.

of $30^{\circ}$ and total erosion, no re-deposition took place to increase vertical load on the foreland and hinterland. The lack of re-deposition eased the formation of new kinks and consequently more kinks developed than in models where sedimentation was applied. Strain partitioning is clearly a close interplay between compaction, slip along the dicollement and slip along imbricate shears, and all are dependent on the rate of erosion and amount of re-deposition in the near vicinity of the wedge.

If models resemble nature and the rigid indenter face-dip is $30^{\circ}$, the more the erosion, the longer time decreasing numbers of successive shears/kinks remain active. As a consequence, areas with rapid erosion will enable high ratios of vertical vs. lateral escape of the orogenic wedge. The extreme case, of total erosion and removal, is not likely in nature. However, the model with total erosion and rigid indenter face-dip of $75^{\circ}$ is an efficient machine leading to vertical escape of basal (deep) crust to the top surface.

Tectonic plate movements with topographic highs and lows have long been known to control the circulations of the atmosphere and ocean and therefore the climate. However, it is also significant that climate in turn controls rate of erosion and therefore the tectonics and the way that orogens partition strain. As shown here erosion and re-deposition influence the slip-rate and time of activity along the faults as well as the evolution of effective indenters and therefore controls the development of thrust patterns in orogens.

Acknowledgments- DS kindly acknowledges the financial support from the General Secretariat for Research and Technology in the frame of the program "EPET II, Metro 4.1, No.97EL-92" for Greek-speaking scientists abroad. KSP has been financially supported by "doktorandtjonst" from Uppsala University. We also thank the two reviewers for comments and constructive criticism. 


\section{REFERENCES}

BEAUMONT, C., FULLSACK, P. \& HAMILTON, J. 1992. Erosional control of active compressional orogens. In Thrust Tectonics, ed. K.R. McClay, pp. 1-18. Chapman and Hall, London.

BEAUMONT, C., FULLSACK, P. \& HAMILTON, J. 1994. Styles of crustal deformation in compressional orogens caused by subduction of the underlying lithosphere. Tectonophysics 232, 119-132.

BONINI, M., SOKOUTIS, D., TALBOT, C.J., BOCCALETTI, M. \& MILNES, A.G. 1999. Indenter growth in analogue models of Alpine-type deformation. Tectonics, 18, 119-128.

BYERLEE, J. 1978. Friction of rocks. Pure and Applied Geophysics 116, 615-626.

COLETTA, B., LETOUZEY, J., PINEDO, R., BALLARD, J.F. \& BALÉ, P. 1991. Computerized X-ray tomography analysis of sandbox models: Examples of thin-skinned thrust systems. Geology 19, 1063-1067.

DAVY, C. \& COBBOLD, P.R. 1988. Indentation tectonics in nature and experiment. 1. Experiments scaled for gravity. Bulletin of the Geological Institutions of Uppsala 14, 129-141.

KOONS, P.O. 1990,. Two-sided orogen: Collision and erosion from sandbox to the Southern Alps, New Zealand. Geology 18, 679-682.

MALAVIEILLE, J. 1984.. Modélisation expérimentale des chevauchements imbriqués: application aux chaînes de montagnes. Bull. Soc. géol. France 7, 129-138.

MERLE, O 1994. Syn-convergence exhumation of the central Alps. Geodinamica Acta 7, 3, 129-138.

MERLE, O. \& ABIDI, N. 1995.. Approche expérimentale du fonctionnement des rampes émergentes. Bulletin de la Sociéte géologique de la France 166, 439-450.

MULUGETA, G. 1988. Modelling the geometry of Coulomb thrust wedges. Journal of Structural Geology 10, 847-859.

MULUGETA, G. \& KOYI, H. 1987. Three-dimensional geometry and kinematics of experimental piggyback thrusting. Geology 15, 1052-1056.

MULUGETA, G. \& KOYI, H. 1992. Episodic accretion and strain partitioning in a model sand wedge. Tectonophysics 202, 319-333.

PERSSON, K. (in press) Effective indenters and the development of double-vergent orogens - insights from analogue sand models, in Koyi, H.A. and Mancktelow, N.S., eds., Tectonic Modeling: A volume in Honor of Hans Ramberg, Boulder, Colorado, Geological Society of America Memoir 193.

RATSCHBACHER, L., MERLE, O., DAVY, P. \& COBBOLD, P. 1991. Lateral extrusion in the eastern Alps, part 1: boundary conditions and experiments scaled for gravity. Tectonics 10, 245-256.

TAPPONNIER, P. \& MOLNAR, P. 1976. Slip-line field theory and large-scale continental tectonics. Nature 264, 319-324.

TAPPONNIER, P., PELZER, G., LE DAIN, A.Y., ARMIJO, R. \& COBBOLD, P. 1982. Propagating extrusion tectonics in Asia: new insights from simple experiments with plasticine. Geology 10, 611-616.

TAPPONNIER, P., PELZER, G. \& ARMIJO, R. 1986, On the mechanism of collision between India and Asia. In Collision Tectonics, eds Coward, M.P. and Ries, A.C., Spec. Publ. Geol. Soc. London 19, 115-157.

THOMPSON, A.B., SCHULMANN, K. \& JEZEK, J. 1997. Extrusion tectonics and elevation of lower crustal metamorphic rocks in convergent orogens. Geology 6, 491-494.

WILLETT, S., BEAUMONT, C. \& FULLSACK, P. 1993. Mechanical model for the tectonics of doubly vergent compressional orogens. Geology 21, 371-374. 